\title{
MicroRNA 21a-5p overexpression impacts mediators of extracellular matrix formation in uterine leiomyoma
}

Eden R. Cardozo ${ }^{1,2,3^{*}}$, Rosemary Foster ${ }^{1}$, Anatte E. Karmon ${ }^{1,2}$, Amy E. Lee ${ }^{1,2}$, Leah W. Gatune ${ }^{1}$, Bo R. Rueda ${ }^{1,2}$ and Aaron K. Styer ${ }^{1,2}$

\begin{abstract}
Background: MicroRNAs (MiR) may promote fibroid development via altered expression of genes involved in cell proliferation and ECM formation, and evidence supports aberrant expression of MicroRNA (MiR) 21a-5p in fibroids. The purpose of this study was to investigate the functional significance of MiR $21 a-5 p$ overexpression in the pathobiology of leiomyomata (fibroids).

Methods: A basic science experimental design using immortalized fibroid and myometrial cell lines derived from patient-matched specimens was used. Stable overexpression of MiR-21a-5p in an immortalized fibroid and patient matched myometrial cell line was achieved through lentiviral vector infection. Main outcome measures were MiR21-5p overexpression, target gene and protein expression, collagen (COL1A1) production, cell proliferation, cell migration, and cell cycle stages of fibroid and myometrial immortalized cell lines.

Results: MiR-21a-5p was overexpressed to similar levels in fibroid and myometrial cell lines after lentiviral infection. Increased expression of miR-21 resulted in increased gene and protein expression of TGF- $\beta 3$ in both fibroid and myometrial cells. Changes in expression of the ECM genes Fibronectin, Collagen 1A1, CTGF, Versican and DPT were seen in both fibroid and myometrial cells. Changes were also seen in Matrix Metalloproteinase (MMP) related genes including MMP 2, MMP 9, MMP 11 and Serpine 1 in both fibroid and myometrial cells. MiR-21 upregulation resulted in increased proliferation and migration in fibroid cells compared to myometrial cells.

Conclusions: MiR-21a-5p overexpression results in changes in the expression of ECM mediators in both fibroid and myometrial cells, and increased cell proliferation in fibroid cells. These finding suggest a potential functional role of MiR-21a-5p in the development of uterine fibroids and warrant further investigation.
\end{abstract}

Keywords: Fibroids, Leiomyoma, miR-21, Extracellular matrix, TGF- $\beta$

\section{Background}

Uterine fibroids, or leiomyoma, represent a major public health problem for women of reproductive age. These benign smooth muscle tumors of the myometrium have a cumulative incidence of nearly $70 \%$ in white women and over $80 \%$ in black women [1]. In the United States, fibroids remain the leading

\footnotetext{
* Correspondence: cardozo.eden@gmail.com

${ }^{1}$ Vincent Center for Reproductive Biology, Vincent Department of Obstetrics and Gynecology, Massachusetts General Hospital, 55 Fruit Street, Yaw 10A, Boston, MA 02114, USA

${ }^{2}$ Department of Obstetrics, Gynecology, and Reproductive Biology, Harvard Medical School, Boston, MA 02115, USA

Full list of author information is available at the end of the article
}

indication for hysterectomy [2], and are estimated to confer a total annual societal cost of up to $\$ 34.4$ billion [3]. Although this is one of the most commonly treated gynecologic disorders, there are no consistently effective medical treatments to prevent fibroid development or to reduce the risk of recurrence. Limitations in current medical treatment underscore the need to improve our understanding of the pathobiology of leiomyoma and to investigate diseaserelevant therapeutic targets.

The most commonly accepted etiology for uterine fibroid development is the transformation of myometrial smooth muscle fibroblasts and dysfunctional extracellular

(c) The Author(s). 2018 Open Access This article is distributed under the terms of the Creative Commons Attribution 4.0 International License (http://creativecommons.org/licenses/by/4.0/), which permits unrestricted use, distribution, and reproduction in any medium, provided you give appropriate credit to the original author(s) and the source, provide a link to the Creative Commons license, and indicate if changes were made. The Creative Commons Public Domain Dedication waiver (http://creativecommons.org/publicdomain/zero/1.0/) applies to the data made available in this article, unless otherwise stated. 
matrix (ECM) formation [4]. Transforming growth factor beta (TGF- $\beta$ ) and its cognate receptor (TGF- $\beta$ R), have been implicated by many investigators as key mediators of aberrant cell signaling which contributes to the development of disease $[4,5]$. Emerging evidence indicates that many additional genetic and epigenetic alterations may regulate the formation of leiomyomas [6, 7]. Specifically, microRNAs (miRs) have been recently implicated as epigenetic mediators in the pathogenesis of fibroids [8]. It has been suggested that miRs may promote fibroid development via altered expression of genes responsible for proliferation, apoptosis, angiogenesis, and ECM formation [7].

MiRs are small, non-coding, stable RNAs approximately 22 base pairs long [9], and are thought to regulate gene expression via gene silencing with either inhibition of translation or degradation of target messenger mRNA [8]. Studies have also demonstrated that a minority of miRs may activate gene targets by directly binding to their promoter regions and result in upregulation of target genes [10]. There is substantial evidence that aberrant miR expression plays a role in the development of multiple malignancies and benign human diseases [8, 11-13]. Differential expression of several miR species in fibroids compared to matched native myometrium has implicated these small non-coding RNAs as possible mediators in the pathobiology of fibroids [14-17].

Overexpression of miR-21 in fibroids (compared to myometrium) has been observed by several independent investigators $[8,16,18]$. Elevated miR-21 has also been reported in several models in cancer biology, and this $\mathrm{miR}$ has been shown to inhibit tumor suppressors, to increase cell proliferation, and to promote tumorigenesis [19-22]. Overexpression of miR-21 has also been observed in myocardial, renal, and pulmonary fibrosis models [23-26]. It is considered a "profibrogenic miR" since it has been shown to target the TGF- $\beta$ downstream signaling inhibitor Smad-7 and to accentuate the profibrotic function of TGF signaling mediators in promoting excessive ECM formation in hepatic cells [27].

Recent evidence suggests that various miRs may regulate cell proliferation and ECM formation in uterine fibroids [15, 28]. Given the known role of miR-21 in targeting tumor suppressors, regulation of the profibrotic TGF $\beta$ pathway in ECM production, and consistent reports of aberrant expression of miR-21 in fibroids in several studies, further investigation of this miR has the potential to delineate the role of miRs in the development of fibroids. The objective of this study is to determine the functional significance of miR-21 overexpression in the pathobiology of uterine leiomyoma. We hypothesize that miR-21 overexpression in uterine fibroid and myometrial cells will impact the mediators of the TGF $\beta$ pathway, and alter the expression of regulators of ECM production.

\section{Methods}

This study was approved by the Partners Healthcare $\mathrm{Hu}$ man Research Committee /Institutional Review Board.

\section{Cell lines / cell culture}

An immortalized fibroid cell line (A006-X) and patientmatched myometrial cell line (A005-X) was obtained from the Henry M. Jackson Foundation for the Advancement of Military Medicine, Inc. as previously described [29-31]. Cells were maintained at $37{ }^{\circ} \mathrm{C}$ in DMEM-F12 supplemented with $10 \%$ fetal bovine serum (FBS), Amphotericin-B anti-fungal reagent, Penicillin/Streptomycin antibiotic, and GlutaMAX supplement (Thermo Fisher Scientific, Waltham, MA).

\section{Lentiviral infections}

Stable miR-21a-5p overexpression of the fibroid cell line was achieved using a SMART choice shMIMIC ${ }^{\mathrm{m}}$ lentiviral microRNA vector (GE Dharmacon, Lafayette, CO) with GFP reporter, non-targeting (NTC) negative controls and Glyceraldehyde-3-Phosphate Dehydrogenase (GAPDH) positive controls according to manufacturer's protocols. Briefly, cells were plated in triplicate in 96 well plates and dilutions of lentiviral particles were prepared to achieve multiplicity of infection (MOI) of 1.0, 2. 5 and 5.0 respectively. Cells were incubated overnight with transduction medium (1:1 mixture of DMEM with cell culture medium as described above, plus polybrene) containing lentiviral particles then the following day cell culture medium was added to wells and plates were returned to the incubator for $96 \mathrm{~h}(\mathrm{hr})$. Knockdown of GAPDH positive control at the mRNA level was verified with RT-qPCR, and fluorescent microscopy was used to confirm efficient infection via TurboGFP ${ }^{\mathrm{mix}}$ expression. Establishment of a stable cell line overexpressing miR21a-5p as well as a stable cell line of NTC was accomplished by selecting for puromycin-resistant cells. RTqPCR (has-miR-21-5p LNA PCR primer set; Exiqon, Vedbaek, Denmark) was used to confirm overexpression of miR-21a-5p in the fibroid and myometrial cell lines. Infections were performed in biological triplicate. For all subsequent experiments, fibroid cells infected at MOI of 5 and myometrial cells infected at MOI of 2.5 were used, as these resulted in similar upregulation of miR-21a-5p in the respective cell lines.

\section{RNA isolation}

RNA was isolated from fibroid and myometrial cells using the mirVana isolation kit (Life Technologies, Carlsbad, CA) according to manufacturer instructions. RNA concentration was quantified using the Nanodrop 2000 Spectrophotometer (ThermoFisher Scientific, Waltham, MA). 


\section{MiR expression real-time $\mathrm{qPCR}$}

MiR polyadenylation and reverse transcription to cDNA was performed using the miRCURY LNA microRNA Universal cDNA synthesis kit (Exiqon) per manufacturer protocol. RT-qPCR was performed according to manufacturer protocol using miRCURY LNA microRNA PCR ExiLENT SYBR Green master mix (Exiqon) and hasmiR-21-5p LNA PCR primer set. In order to detect RNA contamination, a non-targeting negative control (NTC) was included in the RT step. Artificial RNA (Sp6) was added to the reverse transcription step as a positive control to confirm that reverse transcription and amplification occurred equally in all samples. MiR-30c, a ubiquitously expressed miR, was used as an internal control. CFX96 Real-Time PCR Detection System (BioRad, Hercules, CA) was used for DNA amplification. Fluorescence of SYBR green dye bound to dual-stranded DNA was utilized for detection. The real-time thermal cycle program was $95^{\circ} \mathrm{C}$ for $30 \mathrm{~s}$ (s) followed by 40 cycles of $95^{\circ} \mathrm{C}$ for $5 \mathrm{~s}$ and $58^{\circ} \mathrm{C}$ for $30 \mathrm{~s}$.

Experiments were repeated in technical triplicates for each of three infections. Relative changes in MiR expression were calculated using the standard $2^{-\Delta \Delta \mathbf{C T}}$ method [32].

\section{Gene target expression real-time qPCR}

Isolated RNA was used to synthesize cDNA using the Superscript VILO cDNA kit (ThermoFisher Scientific, Cambridge, MA). CFX96 Real-Time PCR Detection System (BioRad, Hercules, CA) was used for DNA amplification. Fluorescence of SYBR green dye bound to dualstranded DNA was utilized for detection. The real-time thermal cycle program was $95^{\circ} \mathrm{C}$ for $30 \mathrm{~s}$ followed by 40 cycles of $95^{\circ} \mathrm{C}$ for $5 \mathrm{~s}$ and $58^{\circ} \mathrm{C}$ for $30 \mathrm{~s}$. Probes, purchased from Invitrogen (Waltham, MA), were designed in house. Resultant levels were compared to those determined in control cells infected with a lentivirus encoding a missense miR (non-targeting control, or NTC). Betaactin was used as the internal control. Experiments were repeated in technical triplicates for each of three infections. Relative changes in gene expression were calculated using the standard 2(-Delta Delta C(T)) method [32].

\section{Western immunoblot}

Immunoblot analysis was performed using protocol as previously described [33]. Antibodies directed against TGF 33 (Santa Cruz Biotchnology, Dallas, TX) and GAPDH (Cell Signaling Technology, Danvers, MA) were used. The dilution for TGF $\beta 3$ was 1:1000 and for GAPDH 1:10,000. A chemiluminescent detection reagent (ECL Prime, GE Healthcare Life Sciences, Pittsburgh, PA) was used to develop the blots and then images were created using the Bio Rad ChemiDoc XRS + Imaging System (BioRad, Hercules, CA) and subsequently analyzed using ImageJ software (National
Institutes of Health, Bethesda, MD). The level of TGF$\beta 3$ was quantitated to the level of GAPDH (loading control).

\section{Collagen (COL1A1) assay}

The amount of type I collagen produced by fibroid and myometrial cells over-expressing miR-21a-5p, as well as non-targeting controls, was quantified using the Human Type I Collagen Detection Kit (Chondrex, Inc., Redmond, WA) with ELISA according to the manufacturers instructions. Cells were pretreated with pepsin and elastase and then capture antibody solution was added to cells and they were incubated overnight at $4{ }^{\circ} \mathrm{C}$. Serial dilutions of standard solution were prepared, samples and standard tubes were mixed, incubated at room temperature for $2 \mathrm{~h}$, then plates were washed and detection antibody was added. Steptavidin Peroxidase was added to each well, and cells were incubated for $1 \mathrm{~h}$, after which the plate was washed and OPD solution (ophenylenediamine dihydrochloride in chromagen dilution buffer) was added. Cells were incubated for $30 \mathrm{~min}$ at room temperature then $50 \mu \mathrm{l}$ of $2 \mathrm{~N}$ sulfuric acid was added to each well. The OD values were read at $490 \mathrm{~nm}$. The concentration of collagen $(\mu \mathrm{g} / \mathrm{ml})$ was plotted against standard values provided by the manufacturer, and the amount human type I collagen in samples was calculated using regression analysis. Experiments were repeated in technical triplicate for each infection.

\section{Cell proliferation assay}

Proliferation was determined by plating the cells in 24well plates and culturing as described above. Fibroid and myometrial cells over-expressing miR-21-5p and nontargeting controls were utilized. Fibroid cells were plated at 5000 cells/well and myometrial cells were plated at 10,000 cells/well. Cells were incubated for 24 and $48 \mathrm{~h}$, cells harvested by trypsinization, and the number of viable cells per milliliter was determined by trypan blue exclusion (Invitrogen, Carlsbad, CA) and cell counting using a Bio-RAD TC10 ${ }^{\text {tw }}$ Automated Cell Counter. Live cells were counted at 24 and $48 \mathrm{~h}$ respectively.

\section{Cell cycle analysis}

Fibroid and myometrial cells over-expressing miR-21a$5 \mathrm{p}$ and non-targeting controls were cultured and then cells were arrested in mitosis by blocking with thymidine, releasing, and then blocking with nocodazole. To accomplish this, when cells reached $40 \%$ confluence, $2 \mathrm{mM}$ thymidine was added and then cultured for $24 \mathrm{~h}$. Thymidine was then removed by washing with 1 xPBS and adding fresh DMEM (culture media) for $3 \mathrm{~h}$ in order to release the cells. Nocodazole $(100 \mu \mathrm{g} / \mathrm{ml})$ was then added to the media for $12 \mathrm{~h}$ then removed by washing with $1 x P B S$ and fresh culture media was added. 
Cells were harvested and fixed in cold 70\% ethanol, then centrifuged and washed twice with PBS. Cells were stained with Live/Dead Fixable Far Red Dead Cell Stain Kit (ThermoFisher Scientific, Waltham, MA) to eliminate dead cells during LSR analysis. Ribonuclease A was added directly to the pellet, then DAPI $(1 \mu \mathrm{g} / \mathrm{ml})$ was added directly to cells in ribonuclease A solution and incubated for $15 \mathrm{~min}$ at room temperature. Cells were examined on a BD LSRII analyzer, and cell cycle analysis was performed using FlowJo software (Treestar Inc., Ashland, OR). Experiments were repeated in technical triplicate for each infection.

\section{Migration assay}

Fibroid and myometrial cells over-expressing miR-21a$5 \mathrm{p}$ and non-targeting controls were utilized in the transwell cell migration assay model. Fibroid cells were plated at 5000 cells/well and myometrial cells were plated at 10,000 cells/well due to faster rate of growth of fibroid cells. Cells that migrated across the membrane (sterile 6 . $5 \mathrm{~mm}$ Corning Transwell with 8um pore polycarbonate membrane inserts [Coring Inc., Coring, NY]) were fixed with Crystal Violet staining solution (Sigma-Aldrich, Natick, MA) and counted at $2.5 \mathrm{~h}$.

\section{Statistical analysis}

For qPCR analyses, comparisons between tissue types were made utilizing ddCP values (fold change, with either myometrium or NTC as reference group). Statistical significance was evaluated with unpaired $\mathrm{t}$-tests and 2way ANOVA. Western immunoblot results are presented as relative to the NTC and statistical significance was evaluated using an unpaired t-test. Collagen ELISA results are presented as absolute numbers and results are analyzed with a 2-way ANOVA. Cell cycle and proliferation assay results for the miR21 infected cell line derivatives are presented relative to the results obtained for the corresponding NTC and also analyzed with 2way ANOVA. Migration data are similarly presented as relative numbers and analyzed using an unpaired t-test. Data were analyzed using Prism software (GraphPad Software Inc., La Jolla, CA).

\section{Results}

\section{MiR-21 expression}

Figure 1 shows the relative expression of miR-21 in fibroid and myometrium after infection with lentivirus based on real time PCR. Results are normalized to a non-targeting control (NTC). The level of miR-21 upregulation was similar between fibroid and myometrium following lentiviral infection.

\section{TGF- $\beta$ family gene and protein expression}

Relative levels of gene expression for TGF- $\beta 3$, TGF- $\beta 1$ and TGF- $\beta$ RII respectively in fibroid and myometrium (compared to their respective NTCs) are shown in Fig. $2 \mathrm{a}$. TGF- $\beta 3$ gene expression was greater in miR-21 upregulated fibroid cells compared to miR-21 upregulated myometrial cells $(p<0.0001)$. An increase was observed in TGF- $\beta 3$ gene expression in miR-21upregulated fibroid cells relative to their NTC $(p=0.04)$. Similar levels of TGF- $\beta 1$ and TGF- $\beta$ RII expression were observed in the

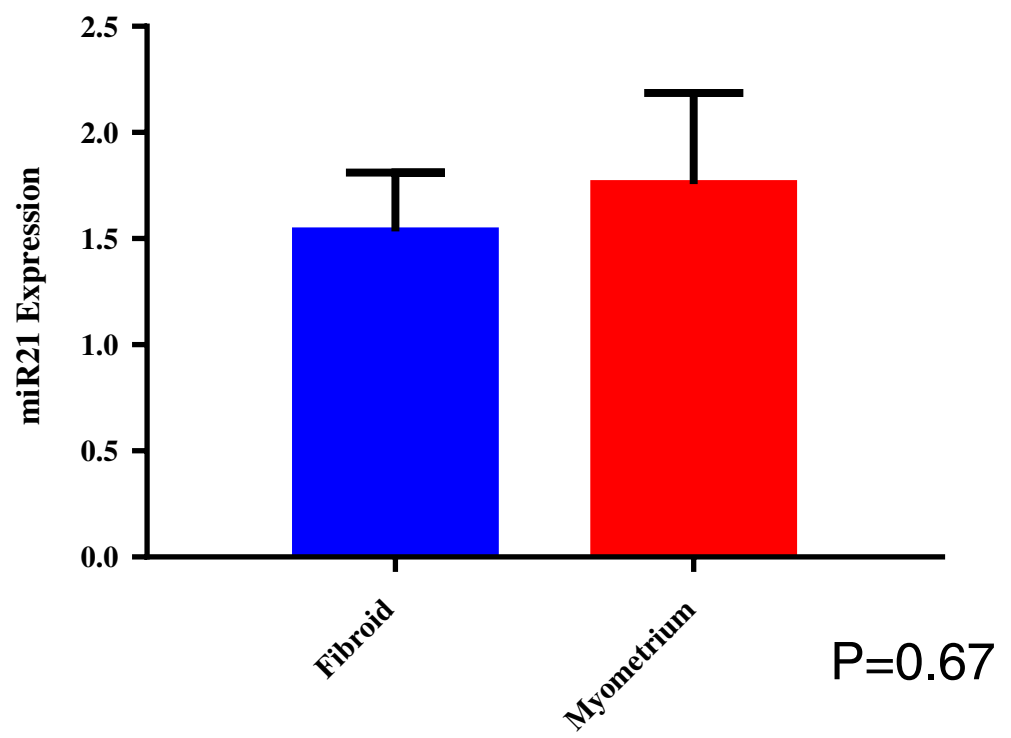

Fig. 1 Relative Expression of miR-21 in Fibroid and Myometrium. RT-PCR relative expression of miR-21 in fibroid and myometrium after infection with lentiviral vector. Results are presented as fold change with non-targeting controls (NTC) as the reference, mean \pm SEM of three independent experiments from each of three independent infections. $P$-value $<0.05$ is indicated by an asterisk 


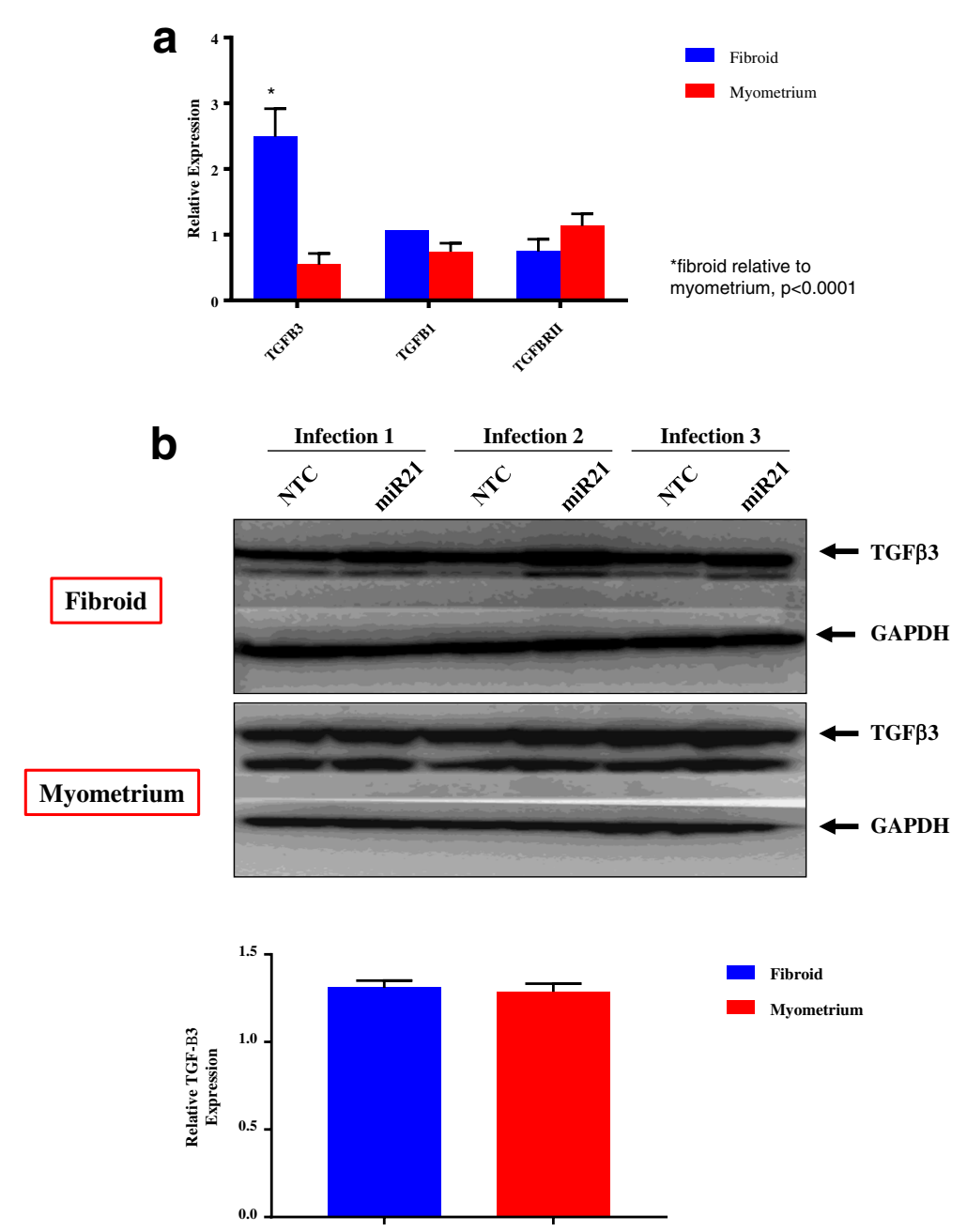

Fig. 2 Gene and protein expression of TGF- $\beta$ family. All results are presented as fold change with NTC as the reference, mean \pm SEM, and $P$-value $<0.05$ is indicated by an asterisk. a Expression of TGF- $\beta$ Family Genes. Gene target RT-PCR relative expression of TGF- $\beta$ family genes in fibroid and myometrial cells upregulated with miR-21. Results represent the mean of three independent experiments from each of three independent infections. b TGF- $\beta 3$ protein expression. Western Blot protein expression of TGF- $\beta 3$ in fibroid and myometrial cells upregulated with miR-21. GAPDH is shown as loading control. Graph shows TGF- $\beta 3$ protein expression (corrected for GAPDH levels) in miR-21 upregulated fibroid and myometrium is normalized to each tissue's respective NTC (corrected for GAPDH levels). Results represent the mean of three independent experiments

infection and NTC group in both fibroids and myometrium respectively.

Assessment of TGF- $\beta 3$ protein expression via Western blot in miR-21 upregulated fibroid and myometrial cells is presented in Fig. $2 \mathrm{~b}$. TGF- $\beta 3$ protein expression was higher in miR-21 upregulated fibroid compared to NTC $(p=0.0149)$ and in miR-21 upregulated myometrium compared to NTC $(p=0.0002)$ (Additional file 1: Figure $\mathrm{S} 1$ ). When TGF- $\beta 3$ protein expression (corrected for GAPDH levels) in miR-21 upregulated fibroid and myometrium is normalized to each tissue's respective NTC (corrected for GAPDH levels), there is no significant difference in TGF- $\beta 3$ protein expression between fibroid and myometrium $(P=0.73)$ (Fig. $2 b)$.

\section{Gene expression of matrix metalloproteinase (MMP) genes}

Figure 3a shows the impact of miR-21 upregulation on the relative expression of ECM related genes. An increase in MMP 2, MMP 9, MMP 11 and Serpine 1 expression in miR-21 upregulated fibroid cells was observed compared to NTC ( $p=0.01,0.009,0.007$ and 0.02 , respectively). Decreased expression of MMP-11 ( $p$ $=0.007)$ and Serpine $1(p=0.03)$ was observed in miR21 upregulated myometrium compared to NTC. When miR-21 upregulated fibroid cells were compared to miR21 upregulated myometrium cells, a difference in MMP$2(p=0.01)$ and MMP-11 $(p=<0.0001)$ expression respectively was observed. 


\section{a}

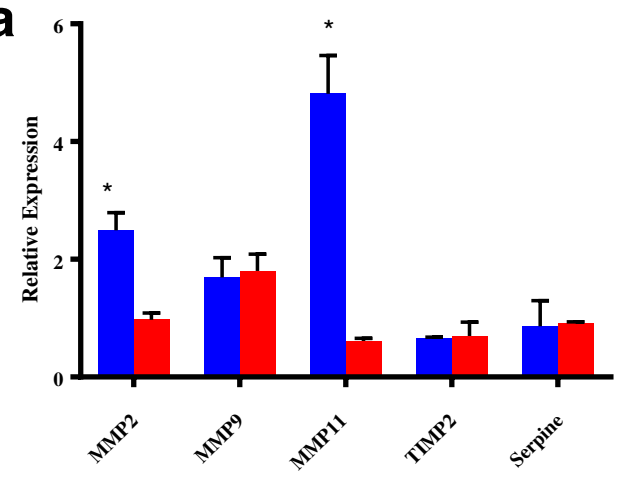

b

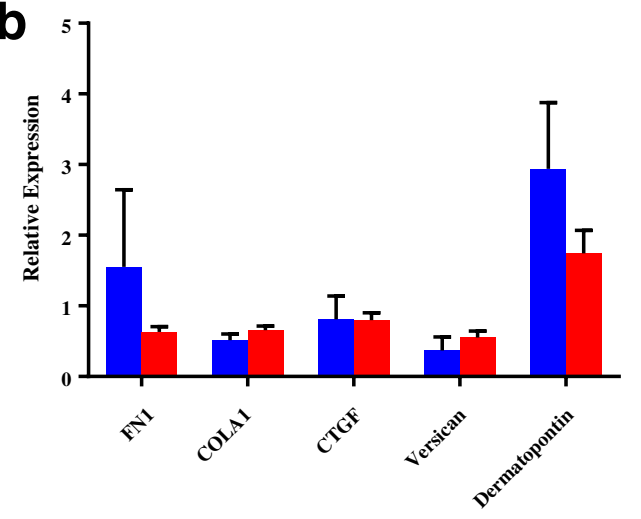

C

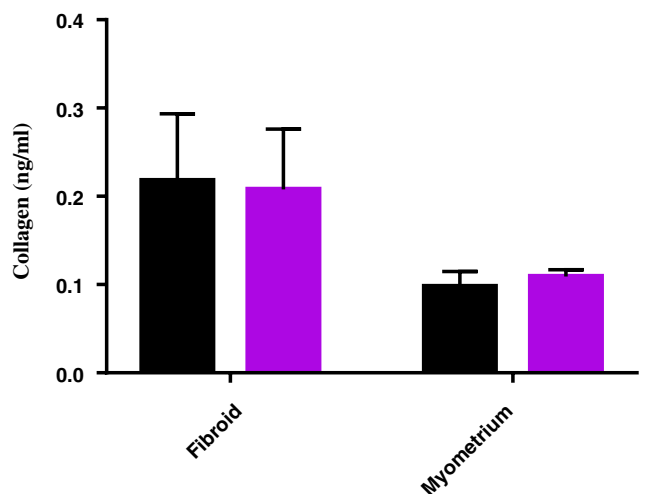

Fibroid

Myometrium

${ }^{*} \mathrm{p}<0.05$ fibroid relative to

myometrium

Fibroid

Myometrium

${ }^{\star} p<0.05$ fibroid relative to

myometrium

NTC

miR21

Fig. 3 Gene and protein expression of Matrix Metalloproteinase (MMP) and Extracellular Matrix (ECM) family. Results are presented as fold change with NTC as the reference, mean \pm SEM of three independent experiments from each of three independent infections. P-value $<0.05$ is indicated by an asterisk. a MMP family. Gene target RT-PCR relative expression of MMP family genes in fibroid and myometrial cells upregulated with miR21. b ECM Family. Gene target RT-PCR relative expression of ECM family genes in fibroid and myometrial cells upregulated with miR-21. c Collagen Assay. ELISA results of Collagen 1A1 protein expression in fibroid and myometrial cells upregulated with miR-21

\section{Gene expression of extra cellular matrix related genes}

The relative gene expression of mediators of ECM formation are presented in Fig. 3b. In miR-21 upregulated fibroid cells, there was a decrease in expression of Collagen 1A1 $(p=0.02)$ and Versican $(p=0.02)$ respectively compared to NTC. In miR-21 upregulated myometrial cells, there was a decrease in the expression of Fibronectin $(p=0.02)$, Collagen 1A1 $(p=0.02)$, CTGF $(p=0.01)$,
Versican $(p=0.02)$ and DPT $(p=0.04)$ respectively in the myometrium. No differences were observed when fibroid and myometrium were compared.

\section{Collagen assay}

No difference was seen in collagen accumulation when comparing miR-21 upregulated fibroid or myometrium 
to NTC or when comparing miR-21 upregulated fibroid with miR-21 upregulated myometrium (Fig. 3c).

\section{Cell proliferation}

In fibroid cells, an increase in cell proliferation in cells with miR-21 upregulation compared to controls $(p<0$. 0001) was observed at the $48 \mathrm{~h}$ time point. No differences were observed in myometrial cells at any time point (Additional file 2: Figure S2). Figure 4a depicts the results of cell proliferation in miR-21 upregulated fibroid and myometrial cells (normalized to respective NTCs), measured at 24 and $48 \mathrm{~h}$ respectively after plating. There was increased proliferation in fibroid cells as compared to myometrial cells at $48 \mathrm{~h}$ after plating $(p<0.001)$.

\section{Cell cycle analysis}

Cell cycle analysis of miR-21 upregulated fibroid compared to myometrial cells (normalized to respective NTCs) are shown in Fig. 4b. Cell cycle analysis of miR21 upregulated fibroid and myometrial cells compared to their respective NTCs are shown in Additional file 3: Figure S3. Upregulation of miR-21 did not have any statistically significant impact on transition through the cell cycle, in fibroid compared to myometrium and fibroid or myometrium compared to their respective NTC.

\section{Migration assay}

Migration of miR-21 upregulated fibroid compared to myometrial cells (normalized to respective NTCs) is presented in Fig. 4c. Increased migration in miR-21 upregulated fibroid cells compared to myometrial cells $(p=0$. 0467) was observed. No difference was observed in the percentage of miR-21 upregulated fibroid cells migrated relative to the fibroid NTC cells, nor in the percentage of myometrial cells migrated compared to their matched myometrial NTCs (Additional file 4: Figure S4).

\section{Discussion}

This study examined the impact of miR-21 overexpression on regulators of ECM formation and functional endpoints in fibroid and myometrial cells. Increased gene and protein expression of TGF- $\beta 3$, and altered gene expression of several well-described mediators of the ECM in both fibroid and myometrial cells was observed. In addition, several cell specific phenotypic changes, including increased proliferation and migration in fibroid cells compared to myometrial cells myometrial cells occurred following upregulation of miR-21.

Given the phenotypic signature of fibroids, aberrant ECM production and progressive growth, our findings expand the understanding of the possible functional significance of miR-21 in the pathobiology and genesis of this reproductive disorder. Although miR-21 overexpression in fibroids has been reported by other investigators
$[16,18]$, several studies that evaluated the role of miR21-5p in the pathogenesis of leiomyoma have been previously retracted $[34,35]$, and the functional significance of this miR in fibroid biology has been incompletely studied [36, 37]. To our knowledge, our study is the first to provide evidence that miR-21 impacts ECM mediators such as TGF- $\beta 3$ and MMPs in uterine fibroids.

TGF- $\beta 3$ has been established as a significant regulator of ECM formation in uterine fibroids $[4,5]$. TGF- $\beta$ is a growth factor that promotes connective tissue formation, and the TGF- $\beta 3$ has been shown to have 3 to 4 -fold higher expression in fibroids compared to matched myometrium $[38,39]$. The intrinsic biological function of TGF- $\beta$, which includes cellular hypertrophy and ECM turnover, are central to various fibrotic disorders, and may be essential to fibroid development and progression [4]. Notably, the use of TGF- $\beta$ signaling inhibitors in rodent fibroid models results in decreased incidence and multiplicity of uterine leiomyoma [40]. Based upon the findings of this study, overexpression of miR-21 in fibroids may play a role in TGF- $\beta 3$ mediated ECM formation in fibroids.

The increased expression of TGF- $\beta 3$,the primary isoform of TGF- $\beta$ found in the uterus [41], and in leiomyoma cells, appears to have an effect on genes encoding collagen formation [38] and several other genes which influence ECM formation. To this end, it may play a role in the excessive and dysregulated ECM production observed in fibroids. Studies exploring the impact of culturing immortalized fibroid and myometrial cells with TGF- $\beta 3$ found increased mRNA and protein production of ECM proteins collagen 1A1 [29, 42], fibronectin $1[29,42]$ and connective tissue growth factor [29] in both cell types, with increased expression in treated myometrial cells to nearly the levels found in leiomyoma cells [29]. Interestingly, in our study, the effect of increased miR-21 and the subsequent increased expression of TGF- $\beta 3$ in fibroid cells had the opposite impact, and resulted in decreased expression of COL $1 \mathrm{~A} 1$ and versican. In myometrial cells, increased miR-21 expression resulted in decreased expression of fibronectin, collagen 1A1, CTGF, versican and DPT. A possible explanation for this difference in results between our study and others is that miR-21 may directly and indirectly target several upstream and downstream mediators of the TGF- $\beta$ pathway, and may result in variable expression of ECM related genes. As a result, further investigation is warranted to evaluate if increased TGF- $\beta 3$ expression is the result of direct targeting of miR-21 or an indirect on mediators of TGF- $\beta$ signaling.

Treatment of fibroid and myometrial cells with TGF$\beta 3$ has also been shown to result in increased expression of GAG-rich versican variant, which plays an important structural role in ECM organization and also influences 

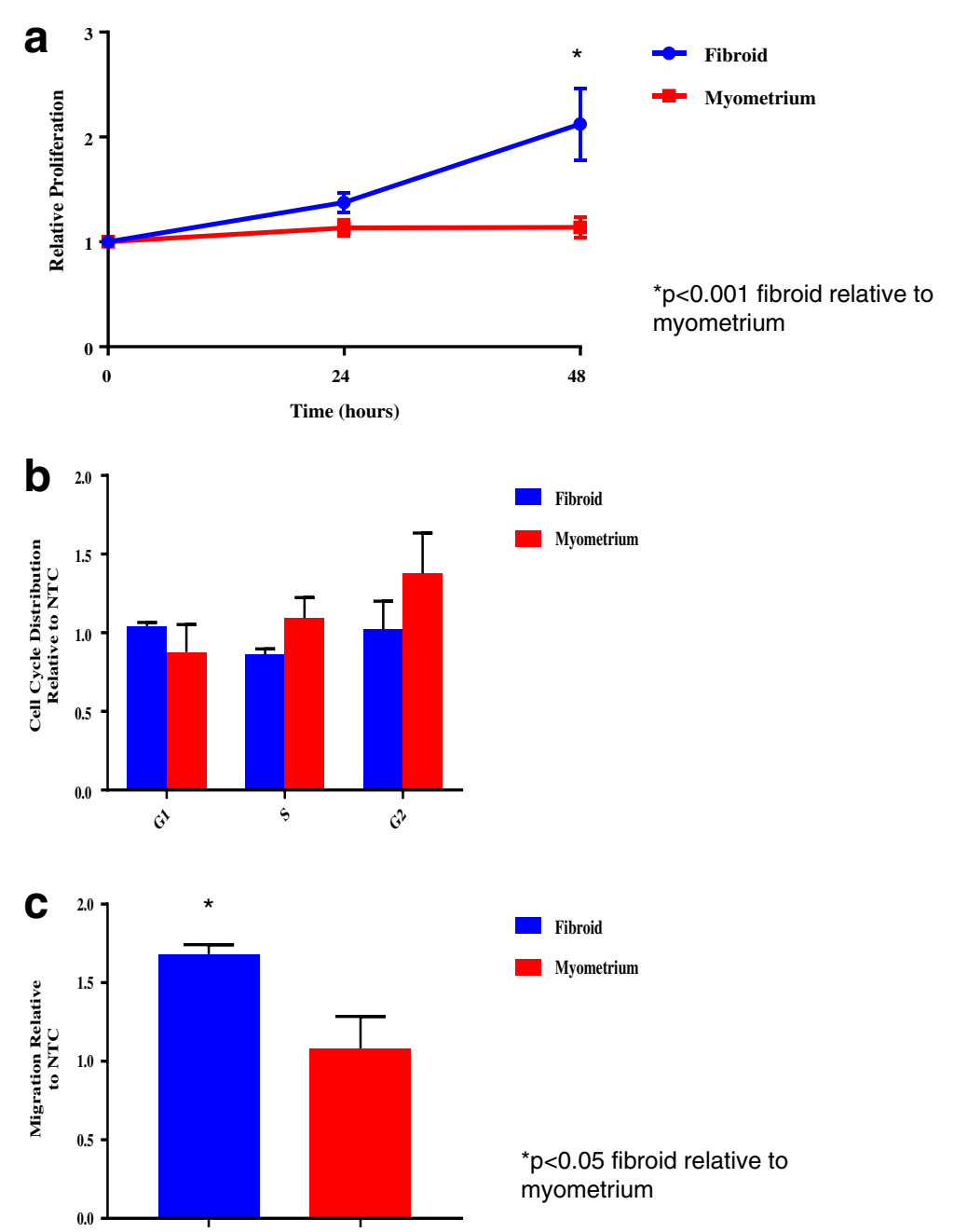

Fig. 4 Cell proliferation, cell cycle analysis and relative migration. Results are presented with fibroid and myometrial cells normalized to NTC as the reference. P-value $<0.05$ is indicated by an asterisk. a Proliferation Assay. Cell proliferation at 24 and $48 \mathrm{~h}$ time points after plating in fibroid compared to myometrial cells upregulated with miR-21. Average cell proliferation by time point is presented as mean \pm SEM of three independent experiments from each of three independent infections. $\mathbf{b}$ Cell Cycle Analysis. Cell cycle analysis of fibroid compared to myometrial cells upregulated with miR-21. Transition through the cell cycle $(G 1, S, G 2)$ is presented as mean \pm SEM of three independent experiments. c Migration Assay. Relative migration of miR-21 upregulated fibroid compared to myometrial cells. Relative migration by time point is presented as mean \pm SEM of each of three independent infections of both fibroid and myometrium

growth and proliferation [39]. While our study showed a decrease in versican expression, fibroid cells with upregulated miR-21 expression, similar to prior studies, did have a significantly increased rate of proliferation. An increase in proliferation is notable since aberrant proliferation is a hallmark of fibroid cells. Notably, migration was increased in miR-21 upregulated fibroid cells compared to myometrium. Given that there was no difference in the amount of miR21 upregulation between fibroid and myometrial cells in this study, these differences may suggest that the functional significance of this miR may be specific to cell type.

Treatment of fibroid cells with TGF- $\beta 3$ has also been shown to induce increased expression of Serpine-1 (plasminogen activator inhibitor-1) protein [42], an inhibitor of matrix-metalloproteinases (MMP). This is consistent with studies showing TGF- $\beta 3$ results in decreased expression of genes for MMP-2 and MMP-11, involved in matrix resorption [29]. In contrast, miR-21 upregulated fibroid cells in this study have increased expression of MMP 2, MMP 9, MMP 11 and Serpine-1, in spite of the associated increase in TGF- $\beta 3$ expression. Again this may reflect the impact on miR-21 at additional targets throughout the TGF- $\beta$ pathway, or at other sites, which impact the expression of ECM-related genes. Furthermore, miR-21 upregulation in myometrial cells resulted in decreased expression of MMP 11 and Serpine 1, providing further evidence that the role of miR-21 differs among specific tissue/cell types. 
While this study highlights the potential impact of miR- 21 and TGF- $\beta 3$ expression in uterine fibroids, further investigation is necessary to better delineate the impact of miR-21 on fibroid pathobiology, especially as it relates to the TGF- $\beta 3$ pathway and the extracellular matrix. Strengths of this study include the use of patient matched fibroid and myometrial cell lines. Long-term lentiviral infection, as opposed to short term transfection, was used to upregulate mir-21 in the fibroid and myometrial cells, which allows for study of the downstream impact of miR-21 over a longer period of time. The functional impact of miR-21 overexpression was examined by evaluating multiple fibroid relevant ECMrelated phenotypic and genotypic endpoints, providing a novel preliminary understanding of the role of miR-21 overexpression in the pathogenesis of uterine fibroids.

Limitations of this study include, as previously noted, the fact that a single miR can have multiple simultaneous targets, which can effect multiple signaling pathways. Therefore overexpression of miR-21 may affect expression of a predicted gene target, such as TGF- $\beta 3$. However, it is unknown if miR-21 is acting directly on this target or via an upstream target in the pathway. Furthermore, as seen with the variable impact of miR-21 on fibroid versus myometrial cells, miRs can act differently in different tissues. Accordingly, the results of this study may not be applicable in other tissue types, and should be interpreted with caution as miR-21 in fibroid and myometrial cells may function differently in vivo versus in vitro. Since this study utilized in vitro models, it is difficult to evaluate the true impact of endogenous sex steroids. Future in vivo studies are needed to understand the influence of endogenous sex steroids on the miR-21 and its role in fibroid pathobiology. Future long-term studies should also aim to assess if miR-21 may be a target for therapeutic intervention that may cause regression of the fibroid phenotype to the normal tissue state. If so, studies will need to determine the most effective way of targeting miR-21 in fibroid tissue only, given that miR-21 is fairly ubiquitous in human tissue.

\section{Conclusions}

In summary, this study has shown that that upregulation of miR-21 resulted in increased gene and protein expression of TGF- $\beta 3$, altered gene expression of several mediators of the ECM in both fibroid and myometrial cells, and phenotypic changes including increased proliferation and migration in fibroid cells. Our findings support the hypothesis that miR-21 may assert its action in fibroid cells in part via the TGF- $\beta 3$ pathway and adds to the increasing evidence for a role of miR-21 in the pathobiology of fibroids. Since fibroid and myometrial cells do not respond in the same fashion to upregulation of miR-21, it may be inferred that miR-21 that the cellular transition from myometrium to uterine fibroids is not solely regulated by miR-21 overexpression. Given the tremendous morbidity and societal cost of uterine fibroids and dearth of effective medical interventions, identification of novel therapeutic targets is critical. This study highlights the importance of miR-21, perhaps via its role in the TGF- $\beta 3$ pathway, as a focus of future investigation in fibroid biology and as a potential therapeutic target in the treatment of uterine fibroids.

\section{Additional files}

Additional file 1: Figure S1. TGF- $\beta 3$ protein expression. TGF- $\beta 3$ protein expression miR-21 upregulated fibroid and upregulated myometrium compared to NTC. Results represent the mean of three independent experiments. (PDF $90 \mathrm{~kb}$ )

Additional file 2: Figure S2. Proliferation Assay. Cell proliferation at 24 and $48 \mathrm{~h}$ time points after plating in fibroid and myometrial cells upregulated with miR-21 compared to their respective NTC. Average cell proliferation by time point is presented as mean \pm SEM of three independent experiments from each of three independent infections. (PDF 96 kb)

Additional file 3: Figure S3. Cell Cycle Analysis. Cell cycle analysis of miR-21 upregulated fibroid and myometrial cells compared to their respective NTCs. Transition through the cell cycle $(G 1, S, G 2)$ is presented as mean \pm SEM of three independent experiments. (PDF $117 \mathrm{~kb}$ )

Additional file 4: Figure S4. Migration Assay. Relative migration of miR21 upregulated fibroid and myometrial cells compared to their respective NTCs. Relative migration by time point is presented as mean \pm SEM of each of three independent infections of both fibroid and myometrium. (DOCX $27 \mathrm{~kb})$

\section{Abbreviations}

ECM: Extracellular matrix; FBS: Fetal bovine serum; GAPDH: Glyceraldehyde-3Phosphate Dehydrogenase; miRs: microRNAs; MMP: Matrix Metalloproteinase; MOI: Multiplicity of infection; NTC: Non-targeting control; TGF-

$\beta$ : Transforming growth factor beta; TGF- $\beta$ R: Transforming growth factor beta receptor

\section{Acknowledgements}

We would like to thank Dr. William Catherino and the Henry M. Jackson Foundation for the Advancement of Military Medicine, Inc.

\section{Funding}

Harvard Catalyst Faculty Fellowship Program-Harvard Medical School (AKS). Vincent Memorial Research Funds (BRR, AKS).

\section{Availability of data and materials}

The datasets used and/or analyzed during the current study are available from the corresponding author on reasonable request.

\section{Authors' contributions}

ERC, RF, AEK, BR and AKS contributed to the conception and design of this study. ERC, AEK, AEL, LWG acquired the data and performed the data analysis. All authors assisted in interpretation of data. ERC drafted the manuscript and RF, AEK, BR and AKS revised it critically. All authors read and gave final approval of the manuscript.

Ethics approval and consent to participate

This study was approved by the Partners Healthcare Human Research Committee /Institutional Review Board.

Competing interests

The authors declare that they have no competing interests. 


\section{Publisher's Note}

Springer Nature remains neutral with regard to jurisdictional claims in published maps and institutional affiliations.

\section{Author details}

${ }^{1}$ Vincent Center for Reproductive Biology, Vincent Department of Obstetrics and Gynecology, Massachusetts General Hospital, 55 Fruit Street, Yaw 10A, Boston, MA 02114, USA. ²Department of Obstetrics, Gynecology, and Reproductive Biology, Harvard Medical School, Boston, MA 02115, USA. ${ }^{3}$ Women and Infants Fertility Center, Brown University Warren Alpert Medical School, 90 Plain Street, Providence, RI 02905, USA.

\section{Received: 12 February 2018 Accepted: 29 April 2018} Published online: 11 May 2018

\section{References}

1. Baird DD, Dunson DB, Hill MC, Cousins D, Schectman JM. High cumulative incidence of uterine leiomyoma in black and white women: ultrasound evidence. Am J Obstet Gynecol. 2003;188:100-7.

2. Wright JD, Herzog TJ, Tsui J, Ananth CV, Lewin SN, Lu YS, Neugut Al Hershman DL. Nationwide trends in the performance of inpatient hysterectomy in the United States. Obstet Gynecol. 2013;122:233-41.

3. Cardozo ER, Clark AD, Banks NK, Henne MB, Stegmann BJ, Segars JH. The estimated annual cost of uterine leiomyomata in the United States. Am J Obstet Gynecol. 2012;206:211 e211-9.

4. Chegini N. Proinflammatory and profibrotic mediators: principal effectors of leiomyoma development as a fibrotic disorder. Semin Reprod Med. 2010;28:180-203.

5. Gauldie J, Bonniaud P, Sime P, Ask K, Kolb M. TGF-beta, Smad3 and the process of progressive fibrosis. Biochem Soc Trans. 2007;35:661-4.

6. Arslan AA, Gold LI, Mittal K, Suen TC, Belitskaya-Levy I, Tang MS, Toniolo P. Gene expression studies provide clues to the pathogenesis of uterine leiomyoma: new evidence and a systematic review. Hum Reprod. 2005;20: 852-63

7. Yang Q, Mas A, Diamond MP, Al-Hendy A. The mechanism and function of epigenetics in uterine leiomyoma development. Reprod Sci. 2016;23:163-75.

8. Karmon AE, Cardozo ER, Rueda BR, Styer AK. MicroRNAs in the development and pathobiology of uterine leiomyomata: does evidence support future strategies for clinical intervention? Hum Reprod Update. 2014;20:760-87.

9. Bartel DP. MicroRNAs: genomics, biogenesis, mechanism, and function. Cell. 2004; 116:281-97.

10. Place RF, Li LC, Pookot D, Noonan EJ, Dahiya R. MicroRNA-373 induces expression of genes with complementary promoter sequences. Proc Natl Acad Sci U S A. 2008;105:1608-13.

11. Lanford RE, Hildebrandt-Eriksen ES, Petri A, Persson R, Lindow M, Munk ME, Kauppinen S, Orum H. Therapeutic silencing of microRNA-122 in primates with chronic hepatitis C virus infection. Science. 2010;327:198-201.

12. Nothnick WB. The role of micro-RNAs in the female reproductive tract. Reproduction. 2012;143:559-76.

13. Volinia S, Calin GA, Liu CG, Ambs S, Cimmino A, Petrocca F, Visone R, lorio $M$, Roldo C, Ferracin M, et al. A microRNA expression signature of human solid tumors defines cancer gene targets. Proc Natl Acad Sci U S A. 2006; 103:2257-61.

14. Chuang TD, Luo X, Panda H, Chegini N. miR-93/106b and their host gene, MCM7, are differentially expressed in leiomyomas and functionally target F3 and IL-8. Mol Endocrinol. 2012;26:1028-42.

15. Chuang TD, Panda H, Luo X, Chegini N. miR-200c is aberrantly expressed in leiomyomas in an ethnic-dependent manner and targets ZEBs, VEGFA, TIMP2, and FBLN5. Endocr Relat Cancer. 2012:19:541-56.

16. Marsh EE, Lin Z, Yin P, Milad M, Chakravarti D, Bulun SE. Differential expression of microRNA species in human uterine leiomyoma versus normal myometrium. Fertil Steril. 2008;89:1771-6.

17. Zavadil J, Ye H, Liu Z, Wu J, Lee P, Hernando E, Soteropoulos P, Toruner GA, Wei JJ. Profiling and functional analyses of microRNAs and their target gene products in human uterine leiomyomas. PLoS One. 2010;5:e12362.

18. Wang T, Zhang X, Obijuru L, Laser J, Aris V, Lee P, Mittal K, Soteropoulos P, Wei JJ. A micro-RNA signature associated with race, tumor size, and target gene activity in human uterine leiomyomas. Genes Chromosomes Cancer. 2007;46:336-47.

19. Akers JC, Ramakrishnan V, Kim R, Skog J, Nakano I, Pingle S, Kalinina J, Hua W, Kesari S, Mao Y, et al. MiR-21 in the extracellular vesicles (EVs) of cerebrospinal fluid (CSF): a platform for glioblastoma biomarke development. PLoS One. 2013;8:e78115.

20. Kan T, Sato F, Ito T, Matsumura N, David S, Cheng Y, Agarwal R, Paun BC, Jin Z, Olaru AV, et al. The miR-106b-25 polycistron, activated by genomic amplification, functions as an oncogene by suppressing p21 and Bim. Gastroenterology. 2009;136:1689-700.

21. Si ML, Zhu S, Wu H, Lu Z, Wu F, Mo YY. miR-21-mediated tumor growth. Oncogene. 2007:26:2799-803.

22. Sun X, Jiao X, Pestell TG, Fan C, Qin S, Mirabelli E, Ren H, Pestell RG. MicroRNAs and cancer stem cells: the sword and the shield. Oncogene. 2014;33:4967-77.

23. He X, Zhang K, Gao X, Li L, Tan H, Chen J, Zhou Y. Rapid atrial pacing induces myocardial fibrosis by down-regulating Smad7 via microRNA-21 in rabbit. Heart Vessel. 2016;31:1696-708.

24. Hennino MF, Buob D, Van der Hauwaert C, Gnemmi V, Jomaa Z, Pottier N, Savary G, Drumez E, Noel C, Cauffiez C, Glowacki F. miR-21-5p renal expression is associated with fibrosis and renal survival in patients with IgA nephropathy. Sci Rep. 2016;6:27209.

25. Kwon OS, Kim KT, Lee E, Kim M, Choi SH, Li H, Fornace AJ Jr, Cho JH, Lee YS, Lee JS, et al. Induction of MiR-21 by stereotactic body radiotherapy contributes to the pulmonary fibrotic response. PLoS One. 2016;11: e0154942.

26. Liu G, Friggeri A, Yang Y, Milosevic J, Ding Q, Thannickal VJ, Kaminski N, Abraham E. miR-21 mediates fibrogenic activation of pulmonary fibroblasts and lung fibrosis. J Exp Med. 2010;207:1589-97.

27. Noetel A, Kwiecinski M, Elfimova N, Huang J, Odenthal M. microRNA are central players in anti- and Profibrotic gene regulation during liver fibrosis. Front Physiol. 2012;3:49.

28. Marsh EE, Steinberg ML, Parker JB, Wu J, Chakravarti D, Bulun SE. Decreased expression of microRNA-29 family in leiomyoma contributes to increased major fibrillar collagen production. Fertil Steril. 2016;106:766-72.

29. Joseph DS, Malik M, Nurudeen S, Catherino WH. Myometrial cells undergo fibrotic transformation under the influence of transforming growth factor beta-3. Fertil Steril. 2010;93:1500-8.

30. Levy G, Malik M, Britten J, Gilden M, Segars J, Catherino WH. Liarozole inhibits transforming growth factor-beta3-mediated extracellular matrix formation in human three-dimensional leiomyoma cultures. Fertil Steril. 2014;102:272-81. e272

31. Malik M, Webb J, Catherino WH. Retinoic acid treatment of human leiomyoma cells transformed the cell phenotype to one strongly resembling myometrial cells. Clin Endocrinol. 2008;69:462-70.

32. Livak KJ, Schmittgen TD. Analysis of relative gene expression data using real-time quantitative PCR and the 2(-Delta Delta C(T)) method. Methods. 2001;25:402-8.

33. Groeneweg JW, Hernandez SF, Byron VF, DiGloria CM, Lopez H, Scialabba V, Kim M, Zhang L, Borger DR, Tambouret $R$, et al. Dual HER2 targeting impedes growth of HER2 gene-amplified uterine serous carcinoma xenografts. Clin Cancer Res. 2014;20:6517-28.

34. Pan Q, Luo X, Chegini N. Differential expression of microRNAs in myometrium and leiomyomas and regulation by ovarian steroids. J Cell Mol Med. 2008;12:227-40.

35. Pan Q, Luo X, Chegini N. microRNA 21: response to hormonal therapies and regulatory function in leiomyoma, transformed leiomyoma and leiomyosarcoma cells. Mol Hum Reprod. 2010;16:215-27.

36. Notice Of Retraction. 'MicroRNA 21: response to hormonal therapies and regulatory function in leiomyoma, transformed leiomyoma and leiomyosarcoma cells' by Qun Pan, Xiaoping Luo and Nasser Chegini, molecular human reproduction (MHR) 16: 215-227 (2010). Doi:10.1093/ molehr/gap093. Mol Hum Reprod. 2012;18:613.

37. Retracted. Differential expression of microRNAs in myometrium and leiomyomas and regulation by ovarian steroids. J Cell Mol Med. 2015; 19:2512.

38. Leppert PC, Catherino WH, Segars JH. A new hypothesis about the origin of uterine fibroids based on gene expression profiling with microarrays. Am J Obstet Gynecol. 2006;195:415-20

39. Norian JM, Malik M, Parker CY, Joseph D, Leppert PC, Segars JH, Catherino $\mathrm{WH}$. Transforming growth factor beta3 regulates the versican variants in the extracellular matrix-rich uterine leiomyomas. Reprod Sci. 2009:16:1153-64.

40. Laping NJ, Everitt Jl, Frazier KS, Burgert M, Portis MJ, Cadacio C, Gold LI, Walker CL. Tumor-specific efficacy of transforming growth factor-beta R inhibition in Eker rats. Clin Cancer Res. 2007;13:3087-99. 
41. Das SK, Flanders KC, Andrews GK, Dey SK. Expression of transforming growth factor-beta isoforms (beta 2 and beta 3 ) in the mouse uterus: analysis of the periimplantation period and effects of ovarian steroids. Endocrinology. 1992;130:3459-66.

42. Halder SK, Goodwin JS, Al-Hendy A. 1,25-Dihydroxyvitamin D3 reduces TGF-beta3-induced fibrosis-related gene expression in human uterine leiomyoma cells. J Clin Endocrinol Metab. 2011;96:E754-62.

Ready to submit your research? Choose BMC and benefit from:

- fast, convenient online submission

- thorough peer review by experienced researchers in your field

- rapid publication on acceptance

- support for research data, including large and complex data types

- gold Open Access which fosters wider collaboration and increased citations

- maximum visibility for your research: over $100 \mathrm{M}$ website views per year 